\title{
Perda de água e modificações anatômicas em folhas de plantas de bananeiras micropropagadas durante a aclimatização
}

\author{
Water loss and anatomical modifications in leaves of micropropagated banana plants during \\ acclimatization
}

\author{
Frederico Henrique da Silva Costa ${ }^{\mathrm{I} *}$ Jonny Everson Scherwinski Pereira ${ }^{\mathrm{II}}$ Moacir Pasqual ${ }^{\mathrm{I}}$ \\ Evaristo Mauro de Castro ${ }^{\mathrm{III}}$ Adriene Matos Santos ${ }^{\mathrm{IV}}$
}

\section{RESUMO}

Estudos sobre os fatores envolvidos na adaptação das plantas micropropagadas ao ambiente ex vitro são imprescindíveis para definir quais os procedimentos devem ser utilizados durante a fase de aclimatização. O objetivo deste trabalho foi avaliar a contribuição da densidade estomática $e$ da presença de cera epicuticular no controle da perda de água, em folhas de bananeiras micropropagadas. Para tanto, brotações axilares oriundas da etapa de multiplicação in vitro foram enraizadas por 24 dias, em meio $M S$, contendo $1 \mathrm{mg} \mathrm{L}^{-1}$ de ácido naftalenoacético (ANA) e $6 g \mathrm{~L}^{-1}$ de ágar e, posteriormente, foram aclimatizadas por 120 dias. Os tratamentos consistiram de folhas formadas in vitro e em diferentes estádios de aclimatização, tais como: T1 - folhas de plantas ao final da fase de enraizamento in vitro; T2 - folhas persistentes de plantas aos 30 dias de aclimatização; T3 novas folhas de plantas aos 30 dias de aclimatização (folhas de transição); T4 - folhas de transição de plantas aclimatizadas por 60 dias; 75 e T6 - novas folhas de plantas aclimatizadas por 60 dias e 120 dias, respectivamente. Foram avaliados os seguintes parâmetros: a densidade estomática, o conteúdo relativo de água e a presença de cera epicuticular. Foi verificado que folhas de plantas provenientes da fase de enraizamento in vitro, em ambiente mixotrófico, apresentam reduzido controle sobre a perda de água e alta densidade estomática. A reduzida transpiração das folhas formadas na fase de aclimatização pode ser atribuída ao menor número de estômatos por unidade de área foliar, à maior capacidade destes em restringir a perda de água e à presença de cera epicuticular.

Palavras-chave: Musa spp., estômatos, transpiração foliar, cera epicuticular.

\section{ABSTRACT}

Studies concerning factors involved in the adaptation of micropropagated plants to ex vitro conditions are indispensable to define which procedures should be used during the acclimatization phase. The objective of this research was to evaluate the presence of stomata and epicuticular wax on water loss control in micropropagated banana plants. For 24 days axillary buds were rooted in MS medium supplemented with NAA (1 $\left.\mathrm{mg} \mathrm{L}^{-1}\right)$ and agar $\left(6 \mathrm{~g} \mathrm{~L}^{-1}\right)$, and afterwards the plantlets were acclimatized for 120 days. The treatments consisted of the evaluation of in vitro leaves and at different acclimatization stages, as follows: T1 - leaves of plants at the end of the in vitro rooting phase $\mathrm{T} 2$ - persistent leaves of plants after 30 days of acclimatization; T3 - new leaves from plants after 30 days of acclimatization (transition leaves); T4 transition leaves from plants after 60 days of acclimatization; T5 and T6 - new leaves from plants after 60 and 120 days of acclimatization, respectively. Data regarding stomatal density, relative water content and presence of epicuticular wax were also evaluated. It was verified that new leaves from plants rooted in vitro under mixotrophic condition presented hight stomatal density and hence a reduced control of water loss. The reduced transpiration of leaves formed during the acclimatization phase can be attributed to the small number of stomata per unit of leaf area associated to the largest capacity of these in restricting water loss, and the presence of epicuticular wax.

Key words: Musa spp., stomata, leaf transpiration, epicuticular wax.

\footnotetext{
'Departamento de Pós-graduação em Fitotecnia, Universidade Federal de Lavras (UFLA), CP 37, 37200-000, Lavras, MG, Brasil.

E-mail: fredericohenrique@yahoo.com.br.*Autor para correspondência.

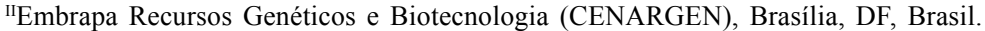

IIIDepartamento de Biologia (DBI), UFLA, Lavras, MG, Brasil.

IvUFLA, Lavras, MG, Brasil.
} 


\section{INTRODUÇÃO}

$\mathrm{Na}$ área de cultura de tecidos de plantas, a micropropagação é considerada a técnica mais estudada e utilizada para multiplicar diversas espécies vegetais, com aplicações práticas comprovadas (ERIG \& SCHUCH, 2005). Em escala comercial, o sucesso dessa tecnologia depende da capacidade da planta produzida em superar, sem grandes estresses, a sua transferência para condições ex vitro a um baixo custo e com altas taxas de sobrevivência e crescimento (HAZARIKA, 2006).

Apesar de as plantas cultivadas in vitro apresentarem aparência normal, estas podem desenvolver características estruturais e fisiológicas não adequadas ao ambiente ex vitro, necessitando, assim, de uma etapa de aclimatização antes de seu cultivo em campo (YOKOTA et al., 2007). Dentre as principais características das plantas cultivadas in vitro, destaca-se a baixa regulação da perda de água, decorrente, principalmente, da limitada ou pouca funcionalidade dos estômatos e da deficiente formação de cera epicuticular (LAMHAMEDI et al., 2003), além de reduzido desenvolvimento do mesofilo foliar, especialmente os parênquimas clorofilianos e feixes vasculares (SANDOVAL et al., 1994; AMÂNCIO et al., 1999; GONÇALVES et al., 2000; ROMANO \& MARTINS-LOUÇÃO, 2003). Os estômatos possuem considerável importância nessas alterações, pois o movimento de água contida nos espaços intercelulares para a atmosfera ocorre quase que completamente por difusão do vapor de água através deles, cujo principal mecanismo de controle é a resistência estomática (TAIZ \& ZEIGER, 2004). Além dos estômatos, a presença de cerosidade, na superfície de folhas formadas in vitro, também possui papel regulatório sobre a elevada transpiração foliar das plantas micropropagadas (LAMHAMEDI et al., 2003).

Pesquisas envolvendo o papel dos fatores estomáticos e não-estomáticos na sobrevivência $e x$ vitro de plantas micropropagadas têm sido incipientes (MAIER \& POST-BEITTENMILLER, 1998). Dessa forma, a realização de estudos que permitam um melhor entendimento dos fatores responsáveis por controlar a excessiva perda de água em plantas oriundas do cultivo in vitro, especialmente após sua remoção dos fracos de cultivo, constitui uma abordagem interessante para aprimorar e/ou desenvolver protocolos mais eficientes de aclimatização, reduzindo perdas e melhorando o crescimento ex vitro das plantas produzidas (GONÇALVES et al., 2000; HAZARIKA, 2006). O objetivo deste trabalho foi avaliar a contribuição da densidade estomática e da presença de cera epicuticular no controle da perda de água, em bananeiras micropropagadas.

\section{MATERIAL E MÉTODOS}

O trabalho foi conduzido no município de Lavras, Minas Gerais (MG), Brasil, a $918 \mathrm{~m}$ de altitude, latitude $21^{\circ} 14^{\prime} \mathrm{S}$ e longitude $45^{\circ} 00^{\prime}$ GRW, entre agosto de 2006 e janeiro de 2007. Como material vegetal, foram utilizadas plantas micropropagadas de bananeira da cultivar Preciosa (AAAB) $(5,0 \mathrm{~cm})$, um híbrido resistente às principais doenças que acometem a cultura da banana. As plantas foram obtidas por meio do enraizamento in vitro, a partir de brotações axilares em meio MS (MURASHIGE \& SKOOG, 1962), suplementado com $1 \mathrm{mg} \mathrm{L}^{-1}$ de ANA (ácido naftalenoacético) e $6 \mathrm{~g} \mathrm{~L}^{-1}$ de agar, $\mathrm{pH} 5,8 \pm 0,1$. O cultivo foi realizado em frascos de $250 \mathrm{~mL}$, contendo $40 \mathrm{~mL}$ de meio e cinco brotações. Esses frascos foram vedados com filme plástico transparente e mantidos em sala de crescimento por 24 dias, a $25 \pm 2^{\circ} \mathrm{C}$ e 16 horas de irradiância $\left(35 \mu \mathrm{mol} \mathrm{m} \mathrm{m}^{-2} \mathrm{~s}^{-1}\right)$ (Osram 20W, luz do dia especial).

Para a aclimatização, as plantas foram inicialmente retiradas dos frascos de cultivo, submetidas à lavagem de suas raízes em água corrente e, posteriormente, à poda manual para o tamanho aproximado de $3 \mathrm{~cm}$. Em seguida, as plantas foram transferidas para tubetes $(0,3 \mathrm{~L})$ contendo terra de subsolo (abaixo da camada de $0-20 \mathrm{~cm}$ ), casca de arroz carbonizada e Plantmax ${ }^{\circledR}$ HT $(1: 1: 1 \mathrm{v} / \mathrm{v})$, adicionados de $50 \mathrm{~g} \mathrm{~L}^{-1}$ de húmus de minhoca e $20 \mathrm{~g} \mathrm{~L}^{-1}$ de superfosfato simples $\left(20 \% \mathrm{P}_{2} \mathrm{O}_{5}\right)$. Em seguida, as mudas foram transferidas para casa de vegetação, onde permaneceram cobertas com filme de polietileno transparente $(150 \mu)$, sombreamento de $70 \%$ (distante 2,70m das plantas) e sistema de irrigação automático por microaspersão (acionado em função da umidade relativa do ar) durante 75 dias. Depois desse período, as plantas foram transferidas para sacos de polietileno preto (4L), contendo o mesmo substrato, mantidas em casa de vegetação desprovida de sombrite, durante 45 dias, e irrigadas manualmente conforme as necessidades.

Os tratamentos consistiram de folhas formadas in vitro e em diferentes estádios de aclimatização, assim descritos: T1 - folhas de plantas ao final da fase de enraizamento in vitro; T2 - folhas persistentes de plantas aos 30 dias de aclimatização; T3 - novas folhas de plantas aos 30 dias de aclimatização (folhas de transição); T4 - folhas de transição de plantas aclimatizadas por 60 dias; e T5 e T6 - novas folhas de plantas aclimatizadas por 60 dias e 120 dias, respectivamente, as quais foram comparadas quanto à densidade estomática, ao conteúdo relativo de água e à presença de cera epicuticular. A segunda 
folha expandida (em direção ápice-base) foi utilizada em todos os tratamentos. O controle das folhas dos tratamentos T2 e T4 foi realizado marcando-se as folhas com fitilhos de cores distintas.

Para os estudos anatômicos, foi utilizada a região mediana da segunda folha expandida coletada de, pelo menos, cinco plantas diferentes, sendo o material fixado em FAA 70, por 72 horas, e conservado em etanol 70\% (v/v) (JOHANSEN, 1940). Os cortes paradérmicos, obtidos à mão livre com auxílio de lâmina de barbear, foram submetidos à clarificação com hipoclorito de sódio (1\%-1,25\% de cloro ativo), lavagem em água destilada e coloração com safranina $1 \%$ e montados em lâminas semipermanentes com água glicerinada (KRAUS \& ARDUIN, 1997). A partir dessas seções, foi avaliada a densidade estomática, sendo expressa em número de estômatos por $\mathrm{mm}^{2}$, segundo a técnica de LABOURIAU et al. (1961). Para essa análise, foi utilizada uma câmara clara com campos de $0,065 \mathrm{~mm}^{2}$ para a contagem de estômatos no terço mediano de cada folha, sendo observados quatro campos de cinco indivíduos por tratamento com o auxílio de um microscópio óptico.

$\mathrm{O}$ conteúdo relativo de água $(\mathrm{RCW})$ foi avaliado a partir de folhas destacadas (segunda folha expandida direção ápice-base). Para isso, folhas excisadas foram mantidas imersas por três horas em água destilada para promover a total turgidez. Após esse período, suas superfícies foram cuidadosamente secas (com papel absorvente), sendo, em seguida, colocadas sob papel alumínio com a superfície abaxial voltada para cima e mantidas em laboratório (cerca de $63 \%$ de umidade relativa). A cada 10 minutos, durante 180 minutos, 12 folhas/tratamento foram pesadas para determinar a massa fresca. Posteriormente, a massa seca das folhas foi também obtida em estufa $\left(50^{\circ} \mathrm{C}\right)$, e o RCW, para cada tempo, foi estimado por: $\mathrm{RCW}(\%)=\left[\left(\mathrm{FW}_{\mathrm{t}}-\right.\right.$ $\left.\mathrm{DW}) /\left(\mathrm{FW}_{\mathrm{s}}-\mathrm{DW}\right)\right] \times 100$, sendo $\mathrm{FW}_{\mathrm{t}}$ a massa fresca ao tempo $t, \mathrm{FW}_{\mathrm{s}}$ a massa fresca inicial (tempo zero) e DW a massa seca (ROMANO \& MARTINS-LOUÇÃO, 2003).

Paralelamente, foram preparadas amostras para microscopia eletrônica de varredura, sendo utilizadas seções foliares do terço médio da segunda folha expandida, as quais foram montadas em suportes de alumínio (stubs), com fita de carbono, e transferidas para dessecador contendo sílica gel. Em seguida, as amostras foram cobertas com ouro no evaporador Balzers SCD 050 e observadas em microscópio eletrônico de varredura (LEO Evo 40) sob $20 \mathrm{Kv}$ e distância de trabalho de $16 \mathrm{~mm}$. O delineamento experimental utilizado foi o inteiramente casualizado, com cinco repetições para o experimento de anatomia e seis repetições para o experimento RCW (com uma média de duas folhas). Este último foi conduzido em parcelas subdivididas no tempo. A análise dos dados foi feita com o software Sisvar (FERREIRA, 2000), por meio de regressão e teste de Scott-Knott $(\mathrm{P} \leq 0,05)$.

\section{RESULTADOS E DISCUSSÃO}

Em relação à densidade estomática, as folhas formadas sob condições in vitro (T1 e T2), embora não tenham diferido significativamente entre si (Tabela 1), apresentam maior número de estômatos por área do que as folhas formadas ex vitro (T3, T4, T5 e T6), tanto para a face abaxial, quanto para adaxial. Esses resultados corroboram aos obtidos para outras espécies, nas quais uma elevada densidade estomática é notada em folhas formadas in vitro, em detrimento das folhas ex vitro, o que é principalmente atribuído à alta umidade relativa do ar no interior dos frascos de cultivo, associada à baixa irradiância da sala de crescimento (SANDOVAL et al., 1994; SCIUTTI \& MORINI, 1995; KHAN et al., 2003). Porém, esse elevado número de estômatos por área e a baixa regulação estomática em folhas in vitro têm se constituído nos principais fatores relacionados à falta ou reduzida capacidade das plantas em controlar a dessecação logo após o transplantio ex vitro (HAZARIKA, 2006). Nessa perspectiva, MARIN et al. (1988) afirmam que a alta umidade nos frascos de cultivo

Tabela 1 - Densidade estomática $\left(\mathrm{n}^{\mathrm{o}}\right.$ de estômatos por $\left.\mathrm{mm}^{2}\right)$ da superfície abaxial e adaxial de folhas de bananeira cultivar Preciosa, oriundas de plantas ao final da fase de enraizamento in vitro e em diferentes estádios de aclimatização.

\begin{tabular}{lcc}
\hline & & \\
Tratamentos $^{*}$ & Abaxial & Adaxial \\
& $102,12 \mathrm{a}$ & $28,68 \mathrm{a}$ \\
T1 & $97,68 \mathrm{a}$ & $32,56 \mathrm{a}$ \\
T2 & $82,88 \mathrm{~b}$ & $17,02 \mathrm{~b}$ \\
T3 & $87,32 \mathrm{~b}$ & $19,98 \mathrm{~b}$ \\
T4 & $72,52 \mathrm{~b}$ & $14,06 \mathrm{~b}$ \\
T5 & $86,58 \mathrm{~b}$ & $19,98 \mathrm{~b}$ \\
T6 & 13,79 & 33,17 \\
CV $(\%)$ & & \\
\hline
\end{tabular}

Médias seguidas pela mesma letra dentro de cada variável pertencem ao mesmo grupo e não diferem entre si, pelo teste de Scott-knott, a $5 \%$ de probabilidade. (C.V.=coeficiente de variação).

* T1 - folhas de plantas ao final da fase de enraizamento in vitro; T2 - folhas persistentes de plantas aos 30 dias de aclimatização; T3 - novas folhas de plantas aos 30 dias de aclimatização (folhas de transição); T4 - folhas de transição de plantas aclimatizadas por 60 dias; T5 - novas folhas de plantas aclimatizadas por 60 dias; e T6 - novas folhas de plantas aclimatizadas por 120 dias. 
afeta o curso do desenvolvimento das células-guarda e os mecanismos de fechamento estomático durante a maturação foliar, embora os estômatos formados in vitro possam também ser competentes para reverter a um estado funcional de maneira relativamente rápida após a remoção das plantas dos frascos de cultivo.

Além disso, SUTTER (1988) sugere a possibilidade de haver diferenças nas respostas dos estômatos em folhas excisadas, em comparação com aquelas intactas e entre diferentes espécies. Segundo esse autor, folhas destacadas de plantas de Prunus cerasus tiveram $75 \%$ dos estômatos fechados após 15 minutos, ao passo que, para macieira, os estômatos permaneceram abertos após a retirada das plantas dos frascos de cultivo. Já em cerejeira, cerca de $78 \%$ dos estômatos foram capazes de fechar após uma hora de exposição às condições de laboratório. Observação semelhante é relatada para estômatos de brotos intactos de macieira, os quais mostraram habilidade para fechar quando expostos a $90 \%$ de umidade relativa, fato evidenciado por um decréscimo na perda de água dos brotos em período superior a 24 horas até taxas constantes (SHACKEL et al., 1990). Além disso, esse estado constante foi mantido ao longo de três dias, o que indicou uma baixa taxa de transpiração cuticular associada à transpiração de alguns estômatos abertos. Portanto, não é possível generalizar que estômatos de quaisquer plantas micropropagadas são incapazes de fechar após exposição ao ambiente ex vitro, seja em resposta ao tratamento químico, à condição de escuro ou ao incremento no gradiente de pressão de vapor de água (HAZARIKA, 2006).

No presente trabalho, a diminuição no número de estômatos por área em resposta à aclimatização ex vitro é semelhante aos resultados relatados em outros estudos (LEE et al., 1985; 1988), sendo, inclusive, um processo característico dessa fase. Essa resposta deve-se, provavelmente, ao aumento na taxa de crescimento das células epidérmicas e dos demais tecidos foliares.

Para o conteúdo relativo de água, os resultados demonstraram uma considerável influência dos diferentes tipos de folhas. Folhas formadas in vitro (T1 e T2) apresentaram perdas significativas de água ao longo do tempo de exposição às condições de laboratório, quando comparadas aos tratamentos T3 e T4 e estes em relação às folhas aos 60 (T5) e 120 dias (T6) ex vitro (Figura 1) $(\mathrm{P} \leq 0.05)$. Adicionalmente, foi verificado que folhas oriundas do cultivo in vitro, quando expostas à desidratação até o período da manhã do dia seguinte, apresentaram excessiva murcha. Quando são consideradas as folhas desenvolvidas in vitro e persistentes na aclimatização (T2), nota-se que estas possuem importância nas semanas subseqüentes ao transplantio, uma vez que tiveram maior conteúdo relativo de água em detrimento do tratamento T1 (Figura 1). Essa resposta indica a existência de algum mecanismo mais eficiente de controle da transpiração, o que é consistente com observações feitas após a transferência para a condição ex vitro, momento em que as folhas formadas in vitro apresentaram sinais de rápida perda de turgescência, porém permaneceram verdes e não senesceram até a formação de novas folhas.

É provável que a excessiva transpiração observada nas folhas in vitro (T1 e T2) se deva à alta densidade estomática, principalmente na face abaxial, ao ineficiente controle de perda de água pelos estômatos e à ausência ou baixa quantidade de cera epicuticular. A análise de regressão referente a esses tratamentos (Figura 1) mostrou um decréscimo acentuado e contínuo ao longo de todo o período de avaliação (180 minutos), evidenciando um elevado nível de estresse hídrico das folhas e a reduzida capacidade dos estômatos de fechar rapidamente. Nesse aspecto, é conhecido que os frascos de cultivo mantêm uma alta umidade, e as plantas crescidas nessa condição abrem seus estômatos para manter um equilíbrio com a atmosfera dos recipientes (SHACKEL et al., 1990), ocorrendo ainda desenvolvimento inadequado dos estômatos, de modo que estes permanecem abertos mesmo após a transferência para a condição ex vitro (SUTTER et al., 1992).

Ao contrário das folhas in vitro, as folhas desenvolvidas após 30 dias de aclimatização (tratamentos T5 e T6) mostraram um maior controle na perda de água e, conseqüentemente, uma maior retenção de água (Figura 1). Possivelmente, a menor densidade de estômatos e a maior funcionalidade dos estômatos formados sob condições ex vitro sejam os fatores responsáveis pelo maior RCW. Isso porque, observando as curvas referentes a esses tratamentos, pode-se sugerir que o controle estomático (abertura e fechamento) ocorre logo nos primeiros períodos de exposição, o que é comprovado pela reduzida declividade da curva (T5) (Figura 1).

No entanto, não apenas os fatores estomáticos têm sido referidos no controle da transpiração em plantas micropropagadas, mas também a presença de cera epicuticular nas folhas formadas $e x$ vitro. Analisando as imagens em microscopia eletrônica de varredura (Figura 2), é possível notar a presença de cera epicuticular nas folhas formadas ex vitro (tratamentos T3, T4, T5 e T6). Em relação às folhas formadas in vitro (T1 e T2), não foi possível analisar a presença de cera epicuticular devido a dificuldades na 


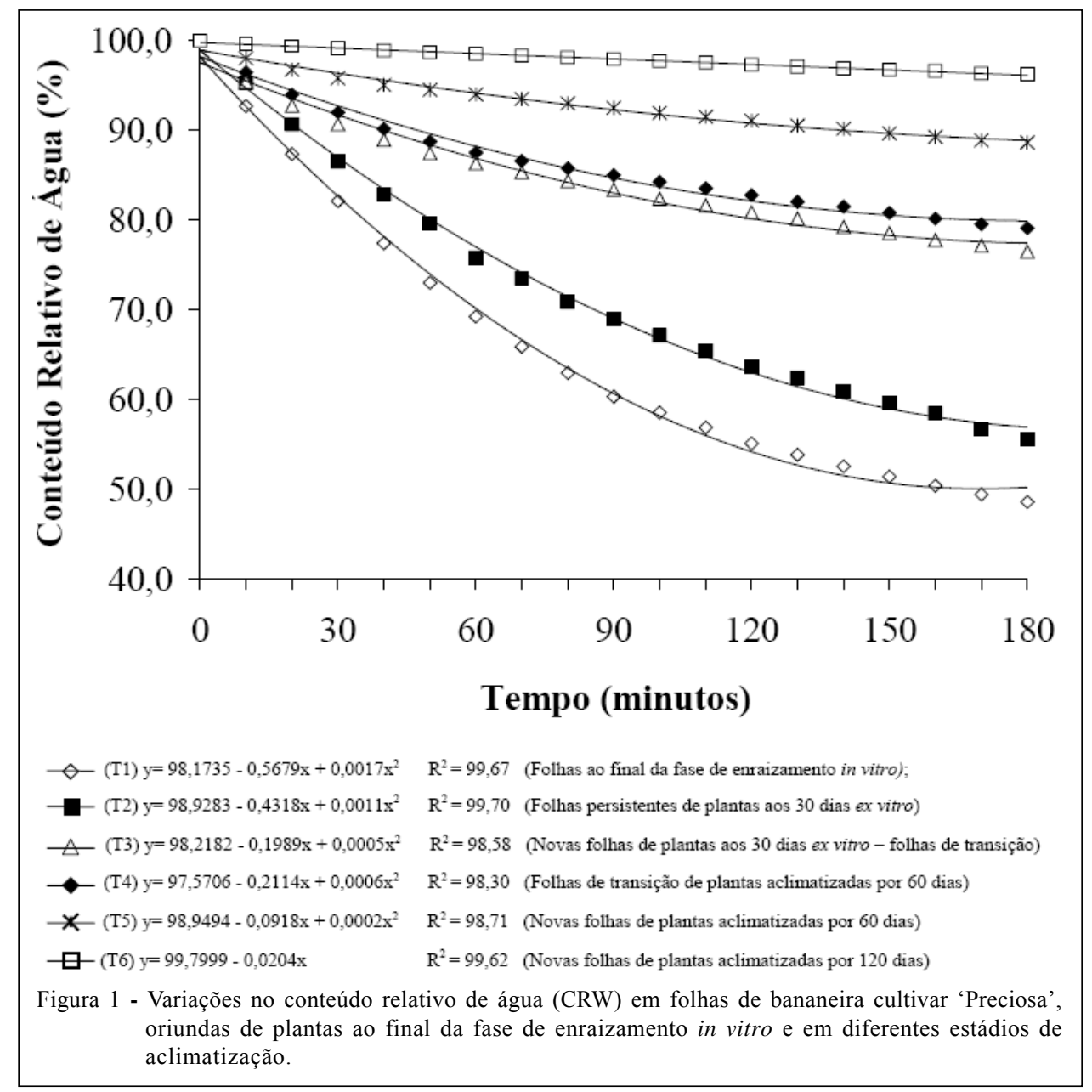

preparação das amostras para microscopia eletrônica de varredura. Redução na formação de cerosidade, em folhas de plantas submetidas às condições mixotróficas in vitro, é reportada por SANDOVAL et al. (1994). De acordo com esses autores, uma baixa quantidade de cera é verificada em folhas de bananeira 'Grande Naine' in vitro, ao contrário do que ocorre em folhas novas formadas ex vitro, sobre as quais a camada de cera se torna gradualmente espessa e mais bem distribuída. Nesse sentido, SCIUTTI \& MORINI (1995) e SUTTER \& LANGHANS (1982) afirmam que a excessiva perda de água em plantas in vitro é resultado da reduzida formação de cera epicuticular.

Reduzido conteúdo relativo de água em tecidos foliares in vitro foi observado por ROMANO \& MARTINS-LOUÇÃO (2003) em carvalho (Quercus suber L.). Segundo esses autores, folhas de plantas in vitro apresentaram uma perda de $53 \%$ do conteúdo relativo de água logo nos primeiros 30 minutos de exposição à temperatura $\operatorname{de} 21^{\circ} \mathrm{C} \pm 2^{\circ} \mathrm{C}$ e umidade relativa de $50 \%$, ao contrário do que ocorreu com folhas novas de plantas após um mês de aclimatização e folhas persistentes, as quais perderam apenas $14 \%$ e $29 \%$ do seu conteúdo de água, respectivamente. Para ARAGÓN et al. (2006), estudos sobre a transpiração de plantas micropropagadas têm mostrado que, nos primeiros dias de exposição às condições ex vitro, ocorre elevada perda de água, sendo que depois disso é verificada redução da transpiração como resultado da adaptabilidade ao novo ambiente.

Dessa forma, os resultados obtidos no presente trabalho contribuem para o entendimento das respostas observadas em plantas micropropagadas de bananeiras quando estas são transferidas para a condição ex vitro, como, por exemplo, a breve e elevada dessecação e o reduzido crescimento nos primeiros dias ex vitro. Além disso, fornecem informações importantes sobre os procedimentos a serem realizados logo após a retirada das plantas dos recipientes e o período subseqüente ao transplantio ex vitro.

Ciência Rural, v.39, n.3, mai-jun, 2009. 

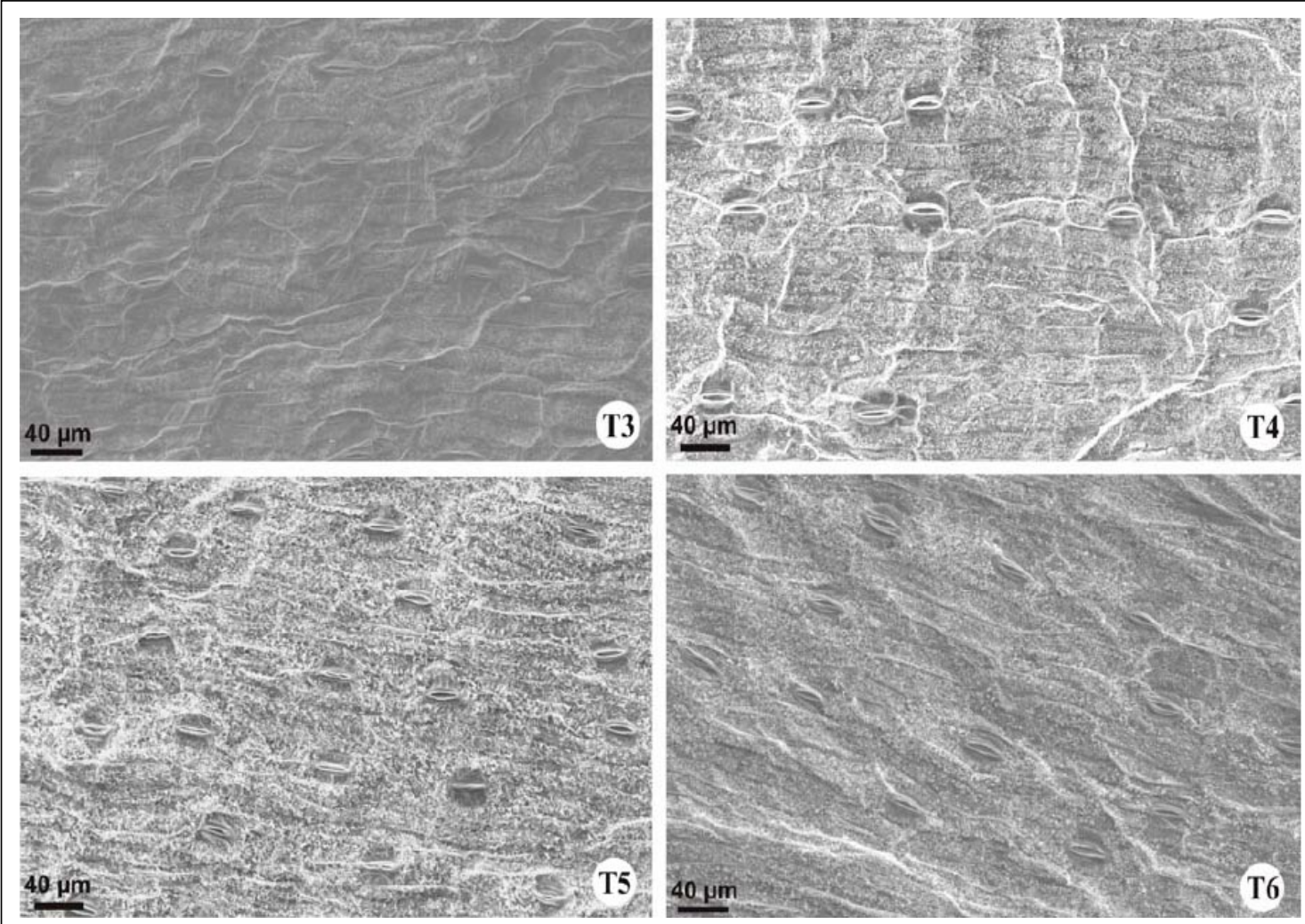

Figura 2 - Aspecto da presença de cera epicuticular na superfície abaxial de folhas de bananeira cultivar 'Preciosa', oriundas de plantas em diferentes estádios de aclimatização. T3 - novas folhas de plantas aos 30 dias de aclimatização (folhas de transição); T4 - folhas de transição de plantas aclimatizadas por 60 dias; e T5 e T6 - novas folhas de plantas aclimatizadas por 60 e 120 dias, respectivamente.

\section{CONCLUSÕES}

Folhas de bananeiras, ao final da fase de enraizamento in vitro, em ambiente mixotrófico, possuem reduzido controle sobre a perda de água e alto número de estômatos por área. A reduzida transpiração das folhas formadas na fase de aclimatização pode ser atribuída ao menor número de estômatos por área, à maior capacidade destes em restringir a perda de água e à presença de cera epicuticular.

\section{AGRADECIMENTOS}

Ao Conselho Nacional de Desenvolvimento Científico e Tecnológico (CNPq), pelo apoio financeiro e pelas bolsas concedidas.

\section{REFERÊNCIAS}

AMÂNCIO, S. et al. Improvement of acclimatization of micropropagated grapevine: photosynthetic competence and carbon allocation. Plant Cell, Tissue and Organ Culture,v.58, p.31-37, 1999. Disponível em: <http:// www.springerlink.com/content/pq8p238t82267780/>. Doi 10.1023/A:1006323129593

ARAGÓN, C. et al. Metabolic importance of starch in the acclimation of plantain 'CEMSA $3 / 4$ ' (AAB) plants. Infomusa, v.15, n.1-2, p.32-35, 2006.

ERIG, A.C.; SCHUCH, M.W. Micropropagação fotoautotrófica e uso da luz natural. Ciência Rural, Santa Maria, v.35, n.4, p.961-965, 2005. Disponível em: <http:// www.scielo.br/scielo.php? script $=$ sci_arttext\&pid $=$ S0103$84782005000400039 \& \ln \mathrm{g}=\mathrm{en} \& \mathrm{nrm}=\mathrm{i}$ so $\& \operatorname{tln} \mathrm{g}=\mathrm{pt}>$. Doi: $10.1590 / \mathrm{S} 0103-84782005000400039$.

FERREIRA, D.F. SISVAR 4. 3: sistema de análise estatística. Lavras: UFLA; Departamento de Ciências Exatas, 2000. Software.

GONÇALVES, J.C. et al. Changes in leaf morphology and anatomy of in vitro-cultured chestnut plantlets during acclimatization. Acta Horticulturae, n.520, p.183-193, 2000.

HAZARIKA, B.N. Morpho-physiological disorders in in vitro culture of plants. Scientia Horticulturae, v.108, p.105120, 2006. Disponível em: <http://www.sciencedirect.com/ science?_ob=ArticleURL\&_udi=B6TC3-4JFHFF0-1\&_user $=6$ $87358 \&$ rdoc $=1 \&$ fmt $=\&$ orig $=$ search $\&$ sort $=\mathrm{d} \&$ view $=\mathrm{c} \&$ acct $=$ C 000037899 \&_version $=1 \&$ \&urlVersion $=0 \&$ \& userid $=$ 
687358\&md5=212dd06ddf65654538e972613dfbbbc $1>$. Doi:10.1016/j.scienta.2006.01.038.

JOHANSEN, B.A. Plant microtechnique. New York: McGraw-Hill Book, 1940. 523p.

KHAN, S.V. et al. Growth and water relations of Paulownia fortunei under photomixotrophic and photoautotrophic conditions. Biologia plantarum, v.46, n.2, p.161-166, 2003. Disponível em: <http://www.springerlink.com/content/ t324q62017356hu8/>. Doi 10.1023/A:1022844720795.

KRAUS, J.E.; ARDUIM, M. Manual básico de métodos em morfologia vegetal. Rio de Janeiro: EDUR, 1997. 198p.

LABOURIAU, L.G. et al. Transpiração de Schizolobium parahyba (Vell) Toledo I. Comportamento na estação chuvosa, nas condições de Caeté, Minas Gerais. Anais da Academia Brasileira de Ciência, v.33, n.2, p.237-257, 1961.

LAMHAMEDI, M. et al. Epidermal transpiration, ultrastuctural characteristics and net photosynthesis of white spruce somatic seedlings in response to in vitro acclimatization. Physiologia Plantarum, v.118, p.554-561, 2003.

LEE, H. et al. Effects of quantum flux density on photosynthesis and chloroplast ultrastructure in tissue-cultured plantlets and seedlings of Liquidambar stryraciflui L. towards improved acclimatization and field survival. Plant Phisiology, v.78, n.3, p.637-641, 1985 .

LEE, N. et al. Quantum flux density effects on the anatomy and surface morphology of in vitro-and in vivo developed sweetgum leaves. Journal of the American Society for Horticultural Science, v.113, n.1, p.167-171, 1988.

MAIER, C.G.; POST-BEITTENMILlER, D. Epicuticular wax on leek in vitro developmental stages and seedlings under varied growth conditions. Plant Science, v.134, p.53-67, 1998. Disponível em: <http://www.sciencedirect.com/ science?_ob=ArticleURL\&_udi=B6TBH-3T1BCVS$6 \&$ _user $=687358 \&$ \&doc $=1 \&$ \& fmt $=\&$ _orig $=$ searc 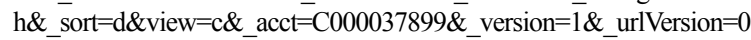 \&_userid $=687358 \& \overline{\mathrm{md}} 5=795363 \mathrm{e} 62 \mathrm{~d} 5 \mathrm{f} 898 \mathrm{aaf} 7 \mathrm{ee} 71 \mathrm{f} 542 \mathrm{ca} 4 \mathrm{e} 3>$. Doi: $10.1016 / \mathrm{S} 0168-9452(98) 00049-1$.

MARIN, A. et al. Stomatal structure and functioning as a response to environmental changes in acclimatized micropropagated Prunus cerasus L. Annals of Botany, v.62, p.663-670, 1988.

MURASHIGE, T.; SKOOG, F.A. A revised medium for rapid growth and bioassays with tobacco tissue cultures. Physiologia Plantarum, v.15, n.3, p.473-497, 1962.

ROMANO, A.; MARTINS-LOUÇÃO, M.A. Water loss and morphological modifications in leaves during acclimatization of Cork Oak micropropagated plantlets. Acta Horticulturae, n.616, p.439-442, 2003

SANDOVAL, J.A. et al. Foliar morphology and anatomy of Musa cv. Grande Naine (AAA) plants grown in vitro and during hardening as compared to field-grown plants. Fruits, v.49, n.1, p.37-46, 1994.

SCIUTTI, R.; MORINI, S. Water loss and photosynthesis of plum plantlets is influenced by relative humidity during rooting in vitro. Journal of Hoticultural Science, v.70, n.2, p.221228,1995 .

SHACKEL, K.A. et al. Stomatal function and cuticular conductance in whole tissue cultured apple plants. Journal of American Society Horticultural, v.115, p.468-472, 1990.

SUTTER, E.; LANGHANS, R.W. Formation of epicuticular wax and its effect on water loss in cabbage plants regenerated from shoot-tip culture. Canadian Journal of Botany, v.60, p.2896-2902, 1982.

SUTTER, E. Stomatal and cuticular water loss from apple, cherry, and sweet gum plants after removal in vitro culture. Journal of American Society for Horticultural Science, v.113, n.2, p.234-238, 1988.

SUTTER, E.G. et al. Acclimatization of tissue cultured plants. Acta Hoticulturae, n.314, p.115-119, 1992.

TAIZ, L.; ZEIGER, E. Fisiologia vegetal. 3.ed. Porto Alegre: Artmed, 2004. 719p.

YOKOTA, S. et al. Histological observation of changes in leaf structure during successive micropropagation stages in Aralia elata and Phellodendron amurense. Plant Biotechnology, v.24, p.221-226, 2007. 